Microscopy

\section{Coming Events}

Due to COVID-19, please check to see if the listed events have been postponed or cancelled.

2021

\section{ABRF 2021}

March 7-10, 2021

Boston, MA

https://web.cvent.com/event/8eb4a085-b3c5-464a-

ba49-023f033a7ee 4 / summary?Refld=ABRF\%20

$2021 \% 20$ Annual\%2OMeeting\%2OHome

Focus on Microscopy 2021

March 28-31, 2021

Porto, Portugal

www.focusonmicroscopy.org

EMAS 2021 - 17th European Workshop on Modern Developments and

Applications in Microbeam Analysis

May 16-20, 2021

Krakow, Poland

www.microbeamanalysis.eu/events/event/60-

emas-2021-17th-european- workshop-on-modern-

developments-and- applications-in-microbeam-analysis

IUMAS-8: 8th Meeting of the

International Union of Microbeam

Analysis Societies

May 24-28, 2021

Banff, Alberta, Canada

www.microbeamanalysis.eu/events/event/

74-iumas-8-8th-meeting-of-the-international-

union-of-microbeam- analysis-societies

mmc2021: Microscience Microscopy

Congress 2021

July 5-8, 2021

Manchester, UK

www.mmc-series.org.uk

Microscopy \& Microanalysis 2021

August 1-5, 2021

Pittsburgh, PA

www.microscopy.org/events/future.cfm

2022

Microscopy \& Microanalysis 2022

July 31-August 4, 2022

Portland, OR

www.microscopy.org/events/future.cfm

2023

Microscopy \& Microanalysis 2023

July 24-28, 2023

Minneapolis, MN

www.microscopy.org/events/future.cfm

2024

Microscopy \& Microanalysis 2024

July 28-August 1, 2024

Cleveland, $\mathrm{OH}$

www.microscopy.org/events/future.cfm

\title{
The Microscopic Structure of Natural Ultra-Black Material
}

\author{
Stephen W. Carmichael \\ Mayo Clinic, Rochester, MN 55905 \\ carmichael.stephen@mayo.edu
}

Ultra-black materials are characterized both by exceptionally low reflectance and high absorbance. Their industrial uses include, among others, the potential to increase photovoltaic cell efficiency, improve stray light capture in telescopes, and inform the design of infrared or radar camouflage. Currently, most synthetic ultra-black materials are made from nano-patterned metals or carbon nanotubes, but these are challenging to manufacture. The nanotubes are extremely susceptible to abrasion and other forms of damage, making them unsuitable for many uses. Alexander Davis, H. Frederik Nijhout, and Sönke Johnsen reasoned that naturally occurring ultra-black materials could offer insight into more robust absorbers for future applications [1].

Some animals have evolved micro- or nanostructures that reflect as little as $0.05 \%$ of visible light. These include several species of birds of paradise, certain peacock jumping spiders, and some swallowtail butterflies. Davis et al. chose to study the structure of ultra-black areas of butterfly wings for three reasons: (i) their scales have evolved several different optical specializations, (ii) the scales are much thinner than other naturally occurring ultra-black materials or synthetic alternatives, and (iii) butterfly scales are both light and robust to be useful in flight. To investigate the general design principles of natural ultra-black materials, they used scanning electron microscopy (SEM), spectrophotometry, and a complex mathematical calculation called finite-difference time-domain modeling. They examined four subfamilies of butterflies: (i) other species of swallowtails, (ii) a group that includes tropical brushfoots, (iii) a group that includes a few of the almost 300 species of milkweed butterflies, and (iv) a group commonly called longwings. As controls, they examined brown or less black butterflies from four genera that contain ultra-black species.

Davis et al. first characterized the structure of scales of 11 butterflies ( 7 ultrablack, 4 controls) using SEM. All of the butterflies had scales with an upper lamina perforated by holes. The holes were honeycombed, chevron-shaped, or rectangular, varying in size from $500 \times 330 \mathrm{~nm}$ to $750 \times 500 \mathrm{~nm}$. Various observations led to the conclusion that shape and size of the holes did not play an important role in ultra-blackness.

Structural features that were consistently found in all the ultra-black specimens were steep longitudinal ridges and robust trabeculae connecting the upper and lower laminae. Control butterflies either lacked or showed significantly reduced trabeculae. Finite-difference time-domain modeling was consistent with the hypothesis that trabeculae or ridges are key structural components for making an ultra-black structure. Other studies led to the conclusion that trabeculae are a more important feature than ridges.

After characterizing the underlying structure, Davis et al. examined the absorbing pigment, melanin. Various studies suggested that melanin's particular optical properties are not necessary to make ultra-black butterfly scales; only a strongly absorbing material is needed. 


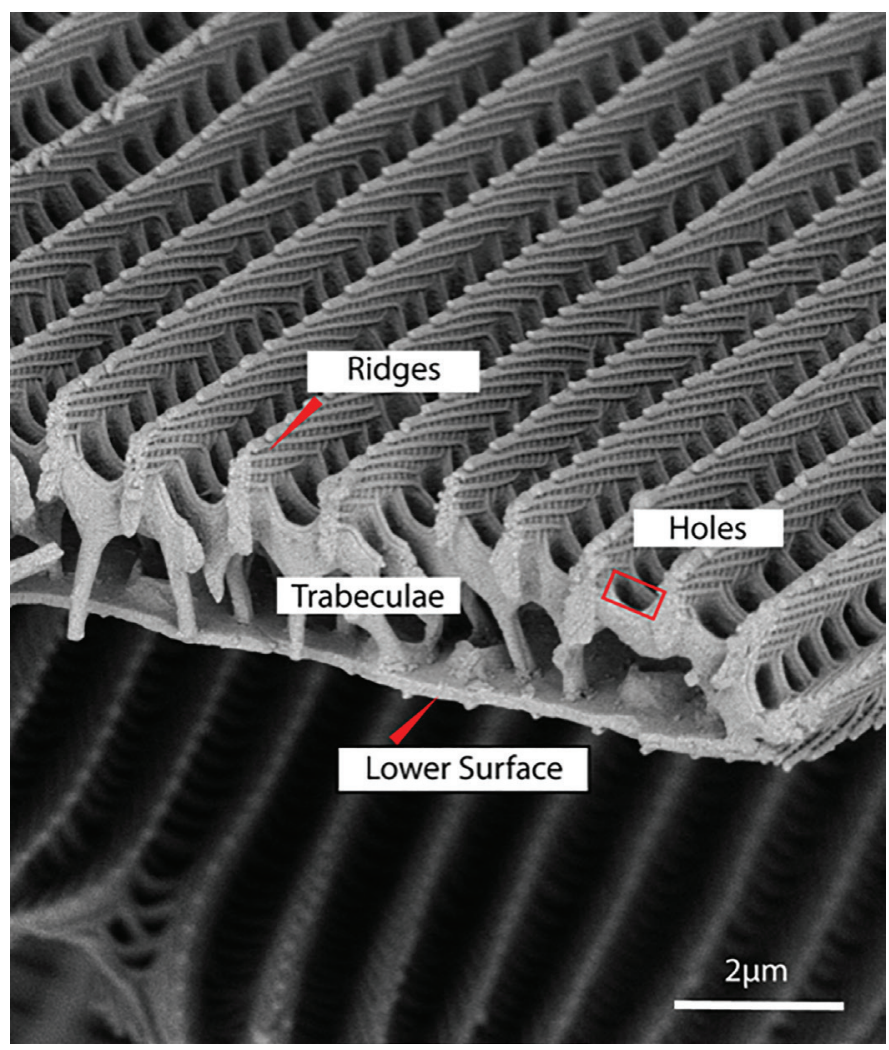

Figure 1: Cross section of an ultra-black scale from the milkweed butterfly Euploea klugii showing the three structrures that contribute to ultra-blackness.
The results of these studies indicated that butterflies have evolved similar features in species in different periods or epochs in time, that is, convergent evolution which creates analogous structures that were not present in the last common ancestor of those groups. The authors hypothesized that because the ultra-black patches always border colored, white, or bright iridescent patches, they are used to increase the perceived brightness and saturation of colors. This may be important in attracting mates and/or making the butterflies appear less appealing to predators (aposematism).

Davis et al. pointed out that ultra-black butterfly scales offer two key advantages for mimicking in a synthetic material: they are thinner than known alternatives, and they can be fabricated at lower temperatures. These findings have important implications for the design of optical instruments, photovoltaic cells and, if scaled up in size, radarabsorbing materials for achieving stealth.

\section{References}

[1] Davis et al., Nat Commun, 11 (2020) 1294. https://doi. org/10.1038/s41467-020-15033-1

[2] The author gratefully acknowledges Alexander Davis for reviewing this article.

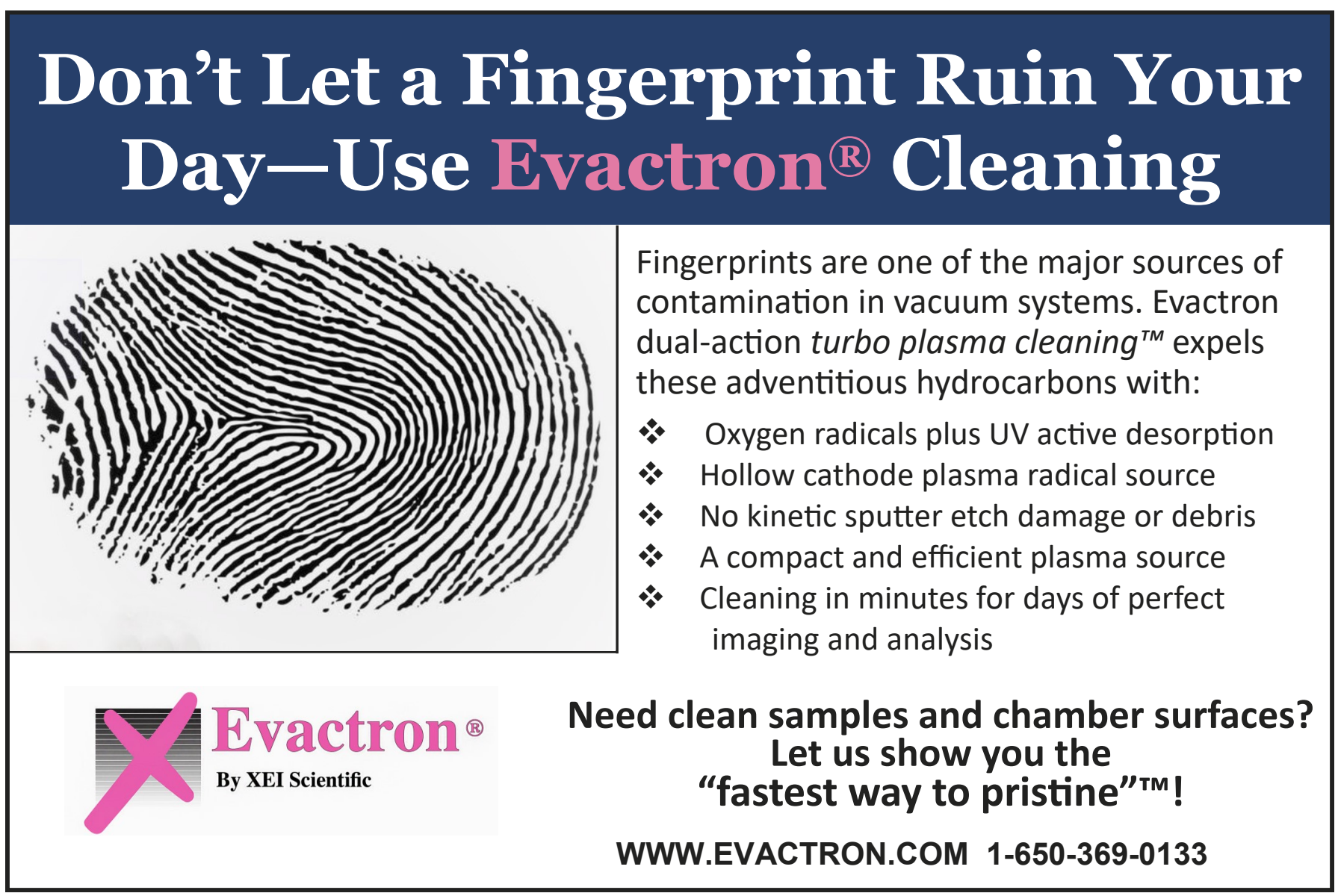


